\title{
Correlation between severity of seizures and anxiety among epileptics: Evidence from a case-control study
}

\author{
Subodh Pandey \\ Associate Professor, Dept. of Physiology, Gandhi Medical College, Bhopal, India \\ Corresponding Author: \\ Email: subodhpandey97@gmail.com
}

\begin{abstract}
Introduction: Very often patients who have epilepsy also develop psychiatric illnesses, most commonly either depression or anxiety or both. The current study was conducted with the objective to determine the correlation between severity of seizures and anxiety symptoms in patients having epilepsy.

Materials and Methods: This was a case-control study. The cases were subjects diagnosed with epilepsy and controls were attendants of other patients who came to the out-patient departments of Hamidia Hospital, Bhopal. A total of 45 cases and 45 sex and age-matched controls were included in the study. The severity of seizures was assessed by the National Hospital Seizure Severity Scale questionnaire. The level of anxiety was assessed both among cases and controls using the Indian version of Taylor's Manifest Anxiety Scale, Developed by D. Sinha in 1961.

Results: $91 \%$ of the control group showed normal anxiety score and $44.4 \%$ of epileptics were categorised as having normal anxiety score. Only $13.3 \%$ of cases reported having very high anxiety score. We observed that the mean anxiety scores of epileptic patients and controls differed very significantly $(\mathrm{p}<0.001)$. The anxiety scores among epileptics showed a positive correlation $\left(\mathrm{R}^{2}=0.49\right)$ with seizure severity scores.

Conclusions: There was a correlation between seizure severity level with the arising anxiety symptoms.
\end{abstract}

Keywords: Anxiety, Epilepsy, Seizure, Severity.

Received: $09^{\text {th }}$ January, 2018

Accepted: $25^{\text {th }}$ January, 2018

\section{Introduction}

People suffering from epilepsy not only suffer from the disease itself but also with social stigma and psychiatric comorbidities such as anxiety, depression, fear, and psychotic disorders. ${ }^{1}$ Numerous studies have provided the evidence that depression and anxiety are more common in epileptic patients than in normal population..$^{2-4}$ The anxiety in epileptic patients can manifest either as an aura, ictal, inter-ictal or postictal episodes. The genesis of anxiety in epilepsy may have numerous causes; seizure, worry and fear of having a seizure are few to mention. ${ }^{5}$ Seizure attack comes at unprecedented times and it has been postulated that it acts as a stimulus which is aversive and out of control of the epileptic patient. Harden et al. suggest that among patient diagnosed with epilepsy, seizure experience can result in anxiety and socially avoidant behaviour. ${ }^{6}$ They also stated that association between seizure severity and seizure worry implies an effect of seizure severity on anxiety. Sometimes seizure disorders can produce an anxiety that is almost indistinguishable from psychiatric disorders. Radiological studies have proven that fear a common manifestation of partial seizures originates in the temporal lobe and on many occasions it can become almost impossible to distinguish it from panic attacks. ${ }^{7}$ Previous studies have reported that the among epileptics the prevalence of inter-ictal anxiety symptoms can be as high as $66 \%{ }^{8}$ In this regard, Neubgebauer et al. (1993) reported that an overlap between seizures and anxiety disorders. ${ }^{9}$ Physicians believe it would be a good idea to investigate the change in the severity of seizures and prevalence of psychiatric symptoms. The purpose of this study was to correlate with severity of seizure and anxiety scores of epileptic patients.

\section{Materials and Methods}

This was a case-control study; the subjects were patients who came to epilepsy clinic in Hamidia Hospital, Gandhi Medical College, Bhopal. Forty-five epileptic patients were included in the study. The inclusion criteria for cases: (i) patient clinically diagnosed with epilepsy and confirmed electroencephalographically by experts. (ii) patient diagnosed with epilepsy for at least two years. Exclusion criteria: (i) patient suffering from neurological disorder other than epilepsy (ii) Patients with a history of head injury. (iii) Patients suffering from chronic illnesses which 
predispose them to anxiety. Controls were the attendants of other patients. The age and sexmatched forty-five healthy individuals were taken under control.

Assessment of Severity of Seizure: The severity of seizure was assessed by Nation Hospital Seizure Severity Scale. ${ }^{10}$

National Hospital Seizure Severity Scale NHSS: The National Hospital Seizure Severity Scale (NHSS) is presented as a refined version of the Chalfont seizure severity scale. ${ }^{10}$ It contains seven seizure-related factors and generates a score from 1-27. An intraclass correlation coefficient of 0.90 was obtained during interobserver and test-retest reliability assessment, suggesting that scale is sufficiently reliable for group studies. The scale was administered in an interview with the patient and an attendant who witnessed the seizure. Based on the seizure scores the patients were divided into four groups; scores above 22 - very severe; 1622 severe, 9-16 moderate, $<9$ as mild.
Assessment of Anxiety Status Tool: Indian version of Taylor's Manifest Anxiety Scale (Developed by D. Sinha 1961). ${ }^{11}$ It is modified version of Taylor's Manifest Anxiety Scale (MAS). The test is having high reliability. The reliability of the split-half method is 0.86 and the reliability index based on Spearman-Brown formula is 0.92 . For assessing the quality of life a questionnaire was introduced containing the 25 questions aimed at identifying the meaning given to the disease, self-concept, and difficulties faced associated feelings with seizure, personal strategies perception of support and other problems. Three closed questions were aimed at identifying epilepsy as a stressor, perception of stigma and perception of seizure control. This questionnaire was used after semantic validation, in such a way that it was easily comprehensible to the patients of the outpatient clinic for epilepsy at this hospital. The study population and control group were asked to fill Sinha's anxiety scale.

\section{Results}

On the basis of the minimum \& maximum scores obtained, four categories of seizure severity were defined. The study population was classified accordingly.

Table 1: Distribution of participants on the basis of NHSS score

\begin{tabular}{|l|c|c|c|c|c|c|}
\hline \multicolumn{1}{|c|}{$\begin{array}{c}\text { Seizure } \\
\text { Severity }\end{array}$} & $\begin{array}{c}\text { Severity Score } \\
\text { Mean } \pm \text { SD }\end{array}$ & $\begin{array}{c}\text { No. of } \\
\text { Patients }\end{array}$ & \% & $\begin{array}{c}\text { Anxiety Score } \\
\text { Mean } \mathbf{S D}\end{array}$ & 'r' & 'p' Value \\
\hline $\begin{array}{l}\text { Very Severe } \\
(>22)\end{array}$ & None & None & NA & NA & NA & NA \\
\hline $\begin{array}{l}\text { Severe } \\
(16-22)\end{array}$ & $17.87 \pm 1.14$ & 16 & $36 \%$ & $48.62 \pm 9.6$ & 0.52 & $<0.001$ \\
\hline $\begin{array}{l}\text { Moderate } \\
(9-15)\end{array}$ & $13.5 \pm 1.66$ & 22 & $49 \%$ & $38.5 \pm 9.6$ & 0.46 & $<0.01$ \\
\hline $\begin{array}{l}\text { Mild } \\
(<9)\end{array}$ & $8.09 \pm 0.99$ & 07 & $15 \%$ & $29.2 \pm 3.6$ & 0.3 & $<0.10$ \\
\hline
\end{tabular}

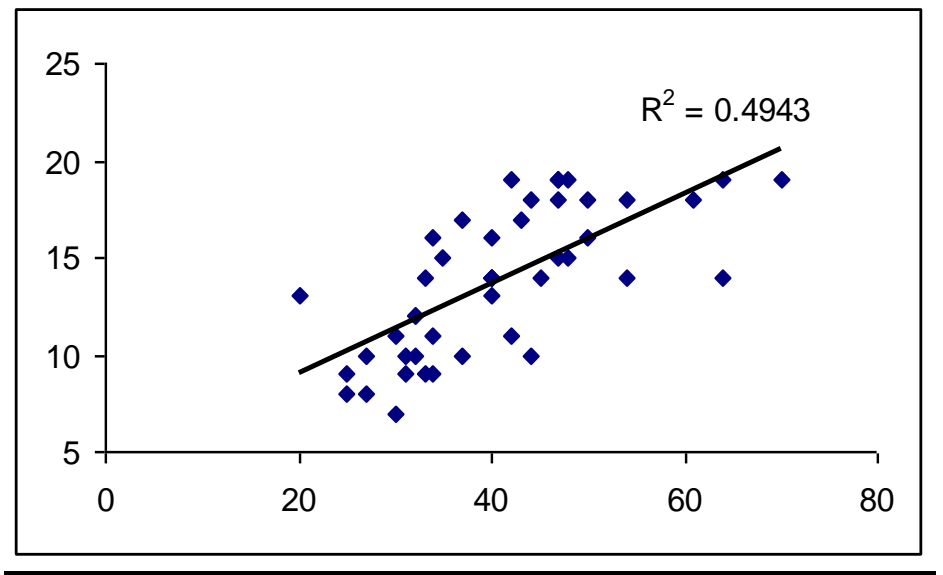

X-axis: Anxiety score; Y-axis: Seizure Severity score

Fig. 1: Correlation of Seizure severity with anxiety score 
Table 1 details the categorization of cases as per NHSS score. It was observed that 16 patient was classified into a severe category, 22 in moderate category and 7 in mild category. The seizure severity and anxiety score could be significantly correlated in the severe and moderate seizure severity groups with correlation coefficient ' $r$ ' 0.52 and 0.46 respectively (Fig. 1). These ' $r$ ' values suggest a moderate correlation between seizure severity and anxiety score. No significant correlation could be established between mild seizure severity and anxiety score. Table 2 details the score of cases and controls obtained from the Indian version of Taylor's Modified Anxiety Scale developed by D. Sinha. As can be observed from table $2,91 \%$ of the control group showed normal anxiety status $(30.08 \pm 4.2)$ and only $9 \%$ were categorised as having high anxiety score. On the other hand, $44.4 \%$ of epileptics were categories in normal anxiety group, $42.2 \%$ in high anxiety group. Only $13.3 \%$ fell in very high anxiety group.

Table 2: Comparison of anxiety scores among cases and controls

\begin{tabular}{|l|c|c|c|c|}
\hline Study Group & Normal (20-35) & High (36-50) & Very high $(>\mathbf{5 0})$ & Mean Anxiety Score \\
\hline $\begin{array}{l}\text { Controls } \\
(\mathbf{n}=\mathbf{4 5})\end{array}$ & $\begin{array}{c}30.08 \pm 4.2 \\
(\mathrm{n}=37)\end{array}$ & $\begin{array}{c}38.19 \pm 5.2 \\
(\mathrm{n}=8)\end{array}$ & - & $31.08 \pm 6.7$ \\
\hline $\begin{array}{l}\text { Epileptics } \\
(\mathbf{n}=\mathbf{4 5})\end{array}$ & $\begin{array}{c}31.04 \pm 3.1 \\
(\mathrm{n}=20)\end{array}$ & $\begin{array}{c}39.12 \pm 5.6 \\
(\mathrm{n}=19)\end{array}$ & $\begin{array}{c}61.08 \pm 6.7 \\
(\mathrm{n}=6)\end{array}$ & $39.8 \pm 11.05$ \\
\hline $\mathrm{t}=4.04 ; \mathrm{P}<0.001$ & \multicolumn{5}{|l|}{} \\
\hline
\end{tabular}

\section{Discussion}

This study provides the evidence that there is an association between seizure severity and anxiety scores of epileptic patients, thus suggesting that severity of seizures may have a role in the genesis of anxiety in epileptic patients. As reported in many previous studies anxiety and depression are the most frequently encountered psychiatric disorders among epileptics. ${ }^{2-4}$ In this study, we observed that there was a significant difference between the mean anxiety scores of epileptic patients and the control group. We also observed that the anxiety scores were significantly higher among cases (epileptic patients) in comparison to control group. We observed that the mean anxiety scores of epileptic patients and controls differed very significantly ( $\mathrm{p}<0.001)$.

Seizure severity and anxiety: In the present study, we observed that there was a positive correlation between seizure severity and anxiety scores of epileptic patients, which was in accordance with the study conducted by Goldstein and Harden. ${ }^{2}$ Goldstein and Harden, reported that there is a positive correlation between seizure severity and anxiety (seizure worry) of epileptic patients, they found that regression between seizure severity and quality of life score. ${ }^{2}$ They suggested that severe and potentially injurious seizure behaviours contribute to anxiety and socially avoidant behaviour for persons suffering from intractable epilepsy. Iqbal et al. also found that there was a significant correlation between the presence of anxiety symptoms and seizure severity levels with $(\mathrm{p}<0.05){ }^{3}$ Goldstein et al. and Harden et al. proposed that anxiety levels were negatively correlated with the seizure frequency in epileptic patients. ${ }^{2}$ Stevanovic et al found that the quality of life of seizure-free adults was comparable with the general population but as the seizure frequency increases patients report impaired quality of life. ${ }^{12}$ The heightened anxiety status of epileptic patients may contribute to the adverse impact on quality of life in epileptic patients. Higher the frequency of seizure, the patient perceives lesser control over the seizures. If seizure frequency increases in epileptic patients then it might also have an impact on the severity of seizure as Devilles et al. stated that seizure experience can result in anxiety and socially avoidant behaviour measured as seizure worry and social functioning. ${ }^{13}$ Devilles et al. proposed model of learned helplessness to people with epilepsy and incorporated seizure severity into the factors contributing to helplessness. ${ }^{13}$ They found that seizure severity and frequency and perceived controllability of seizure contribute significantly to learned helplessness scale scores. ${ }^{13}$ These findings suggest seizure severity and frequency may affect anxiety in person with epilepsy. In the present study, the regression between seizure severity and anxiety score of patients categorized in severe and moderate groups showed moderate association while in patients having mild seizure severity showed no correlation between regressions. It is quite possible that over a period of time patients with epilepsy learns about the semiology of epilepsy and gets acquainted with certain aspects of the disease but the unpredictability of seizure attack possibly puts the patient into a life-threatening situation and in socially unacceptable situations which all may be predisposing the epileptic patients for anxiety. Our findings suggests that 
seizure severity can have an impact in the genesis of anxiety and it might be possible that if measures are taken to reduce the severity of seizure the associated anxiety can be attenuated and will improve the quality of life of epileptics.

\section{Limitations}

The study population was small and the same finding cannot be extrapolated to the general population per se. In this study, only GTCS patients have included the occurrence of anxiety a severity of seizure may well differ in other types of epilepsies.

\section{Conflict of interest}

The authors declare that he has no conflicts of interest.

\section{References}

1. Manchanda R. Psychiatric disorders in epilepsy: clinical aspects. Epilepsy \& Behavior. 2002 Feb 28;3(1):39-45.

2. Goldstein MA, Harden CL. Continuing exploration of the neuropsychiatry of seizures: a review of anxiety and epilepsy. Epilepsy Behav. 2000;1:228-34

3. Iqbal KM, Rambe AS, Sjahrir H. Correlation between Anxiety and Depression Symptoms with Seizure Severity in Epilepsy Patients at Neurology Department Haji Adam Malik Hospital Medan, North Sumatra, Indonesia. BERSAMA KITA MAJU. 2006:87.

4. Piazzini A, Canevini MP, Maggiori G, Canger R. Depression and anxiety in patients with epilepsy. Epilepsy \& Behavior. 2001 Oct 31;2(5):481-9.

5. Swinkels WA, Kuyk J, De Graaf EH, Van Dyck R, Spinhoven PH. Prevalence of psychopathology in Dutch epilepsy inpatients: a comparative study. Epilepsy \& Behavior. 2001 Oct 31;2(5):441-7.

6. Attarian H, Vahle V, Carter J, Hykes E, Gilliam F. Relationship between depression and intractability of seizures. Epilepsy \& Behavior. 2003 Jun 30;4(3):298-301.

7. Baker GA, Jacoby A, Buck D, Stalgis C, Monnet D. Quality of life of people with epilepsy: a European study. Epilepsia. 1997 Mar 1;38(3):353-62.

8. Beyenburg S, Mitchell AJ, Schmidt D, Elger CE, Reuber M. Anxiety in patients with epilepsy: systematic review and suggestions for clinical management. : Epilepsy Behav. 2005 ;Sep;7(2):161-71

9. Pincus JH, Tucker GJ. Behavioral Neurology. Oxford University Press; 2002 Oct 3.

10. O'donoghue MF, Duncan JS, Sander JW. The national hospital seizure severity scale: a further development of the Chalfont seizure severity scale. Epilepsia. 1996 Jun 1;37(6):563-71.

11. Sinha D. Development of two anxiety scales. Manas. 1961;1:1-0.

12. Stevanovic D, Jancic J, Lakic A. The impact of depression and anxiety disorder symptoms on the health- related quality of life of children and adolescents with epilepsy. Epilepsia. 2011 Aug $1 ; 52(8)$.

13. Devellis RF, Devellis BM, Wallston BS, Wallston KA. Epilepsy and learned helplessness. Basic Appl Social Psychol 1980;1:241-53.

\section{Source of funding: None}

